\title{
The role of demographic and clinical characteristics on risk of COVID-19 related infection and mortality
}

\author{
A. O’Shea ${ }^{1,2}$, M. Youssef ${ }^{3}$, M. Connolly ${ }^{1,3}$, A. Al Lawati ${ }^{3}$, S.I. Shah ${ }^{3}$, S. Walsh ${ }^{3}$, D. McCartney ${ }^{1}$ \\ and J. Faul ${ }^{3,4}$ \\ ${ }^{1}$ School of Biological and Health Sciences, Technological University Dublin, Dublin, Ireland, \\ ${ }^{2}$ School of Medicine, Trinity College Dublin, Dublin, Ireland, \\ ${ }^{3}$ Department of Respiratory Medicine, Connolly Hospital Blanchardstown, Dublin, Ireland and \\ ${ }^{4}$ James Connolly Memorial Asthma Research Centre, Royal College of Surgeons in Ireland, Connolly Hospital \\ Blanchardstown, Dublin, Ireland
}

Since the emergence of the severe acute respiratory syndrome coronavirus 2 (SARS-CoV2) which causes Covid-19, global health systems have struggled to cope with the rising number of related infections, acute admissions and mortalities. Poorer clinical outcomes have been observed amongst older patients with Covid-19 and males, and in those who are obese or who have darker skin ${ }^{(1)}$. Additionally, poorer outcomes including increased mortality have been associated with low vitamin D status ${ }^{(2,3)}$. The current observational study aimed to elucidate the association between patient demographic, anthropometric, clinical and biometric characteristics and Covid-19 disease severity and mortality.

Demographic, anthropometric, clinical and biometric patient data were collected from one hundred and fourteen $(\mathrm{n}=114)$ hospitalised Covid-19 patients from Connolly Hospital, Blanchardstown. Data were transferred to IBM SPSS Statistics version 26 (IBM Corporation, Armonk, New York) for statistical analysis. Univariate regression analyses were performed to elucidate the association between demographic, anthropometric, clinical and biometric patient characteristics and Covid-19 related mortality. Multivariate regression analyses were subsequently performed to examine the persistence of these relationships when potential confounders were accounted for.

Male gender (64\%), age $>50$ years $(57.1 \%)$ and overweight or obesity $(75.4 \%)$ were common amongst these hospitalised Covid-19 patients. The majority $(\mathrm{n}=94)$ had measured $25(\mathrm{OH}) \mathrm{D}$ levels, with vitamin $\mathrm{D}$ deficiency $(25(\mathrm{OH}) \mathrm{D}<30 \mathrm{nmol} / \mathrm{l})$ affecting $52.1 \%$. Univariate regression analysis revealed that age $>80$ years (OR 120,95\% CI 6.95-2184.36, p $=0.001)$, obesity $($ OR 6.11 , 95\% CI $1.06-35.35, \mathrm{p}=0.043)$ and vitamin D deficiency (OR 8.0, 95\% CI 0.98-65.62, p $=0.053$ ) were associated with an increased risk of Covid-19 related mortality. Mean vitamin D levels were significantly lower in patients who died (25.1 nmol/L) than in patients who survived $(41.9 \mathrm{nmol} / \mathrm{L}, \mathrm{p}<0.001)$. Vitamin D sufficiency $(25(\mathrm{OH}) \mathrm{D}>50 \mathrm{nmol} / \mathrm{l})$ was more common in those who survived than in those who died $(30.8 \%$ vs. $6.7 \% ; p=0.048)$. In multivariate regression analysis, age over 80 years $(\mathrm{OR} 34.1,95 \% \mathrm{CI}$ 1.56-1009.26, $\mathrm{p}=0.041$ ) and obesity (OR 18.3, 95\% CI 1.91-176.40, $\mathrm{p}=0.012$ ) remained significant risk factors for mortality, even after adjustment for potential confounders.

This study shows that risk of death from Covid-19 is higher in patients who are obese and amongst those aged over 80 years. The data are also suggestive of an association between vitamin D deficiency and increased Covid-19 mortality.

\section{Acknowledgements}

I wish to acknowledge the contribution of Professor John Faul and his team at Connolly, Hospital, Blanchardstown who undertook extensive data collection as part of a clinical audit of outcomes following SARSCov-2 infection and provided such data for analysis in this study. Additionally, I wish to acknowledge the contribution of my thesis supervisor, Dr. Dan McCartney, who oversaw the data analysis and provided endless advice and support throughout the course of the study. I also wish to acknowledge the support offered by my fellow student, Meabh Connolly, who I worked alongside throughout the course of the study. Lastly, I wish to acknowledge the support offered by my family for the duration of the study.

\section{References}

1. Williamson EJ, Walker AJ, Bhaskaran K, et al. (2020) Nature 584, 430-436.

2. Faul JL, Kerley CP, Love B, et al. (2020) Ir Med J 113(84).

3. Radujkovic A, Hippchen T, Tiwari-Heckler S, et al. (2020) Nutrients 12, 2757. 